HISPANICA37 (1993)

\title{
Caracterización y estructuras del verbo compuesto*
}

\section{Kazumi KOIKE}

\section{O. Objetivo}

Este artículo tiene por objetivo delimitar las características gramaticales del verbo compuesto y presentar sus estructuras sintácticas. En los ejemplos (1) a (4) aparecen posibles verbos compuestos: "dar permiso", "poner en alquiler", "andar con chismes" y "hacer efectivo".

(1) ¿ ¿Y quién le ha dado permiso para entrar? (Torrente Ballester, III -17)

(2) $\mathrm{Al}$ interlocutor le interesa ahora poner en alquiler su piso. (El País, 14-05-89)

(3) A Pepe le gusta andar siempre con chismes y habladurías. (Ken)

(4) Los administradores de Banca Catalana hicieron efectiva anoche la dimisión irrevocable de sus cargos. (El País)

\section{Características del verbo compuesto}

Entendemos por verbo compuesto el sintagma verbal que, formado por un verbo soporte (el más común es "hacer") y otros elementos como un sustantivo, un adjetivo o un sintagma preposicional, funciona como un verbo simple. En este apartado, vamos a resumir algunos rasgos fundamentales que caracterizan al verbo compuesto formado por un verbo y un sustantivo, la combinación más representativa del verbo compuesto.

\section{1-1. Denominación}

Han aparecido hasta ahora bastantes denominaciones para designar tanto al sintagma verbal al que llamamos «verbo compuesto» como al verbo componente de dicho sintagma. A continuación pasamos a recopilar las denominaciones aparecidas hasta ahora junto con una serie 
de ejemplos, que van entre paréntesis. Téngase en cuenta que no todos los términos se refieren a una unidad de la misma índole:

Giry-Schneider (1987, p.5) : «les expressions composées d'un verbe support et d'un nom associé à un verbe» ("faire une excursion")

Malero y Gracia (1990): «construcciones de verbo soporte» ("dar un paseo")

Solé (1966) $)^{1}$, citado en Giry-Schneider(1987, p.6-7): «verbo léxicofuncional» ("hacer un repaso", "hacer alusiones", "hacer investigaciones")

Cano (1981, p.50-53): «grupo verbal» o «lexía verbal compleja» ("hacer mención de algo", "hacer colección de algo", "hacer uso de algo") Häusermann(1977)2), citado en Haensch et al. (1982, p.257): «perífrasis del verbo» ("poner término a algo", "tomar parte en algo") Dubský (1990, p.111) : «verbos formemáticos» ("dar un grito")

La denominación de "verbo soporte" proviene del término "verbe support” empleado por los gramáticos franceses." Solé (1966) y Cano (1981) hablan sólo del verbo "hacer". Dubský (1990) , que prefiere hablar de "verbos formemáticos", cita una serie de denominaciones aparecidas hasta hoy día, que son las siguientes: "formas descompuestas", "Funktionsverbgefüge", "predicados analíticos", "sememas construidos", "lexemas verbales complejos", etc.

\section{1-2. Estructura}

El verbo compuesto está formado por un verbo soporte (Vsop., en adelante) y por un sustantivo predicativo. El verbo soporte es un verbo funcional capaz de hacer funcionar al sustantivo como un verbo. Veamos un ejemplo. En el caso del verbo compuesto «dar permiso», el «dar» es un verbo soporte y el sustantivo «permiso» es un sustantivo predicativo, lo cual puede esquematizarse:

«dar [Vsop.] + permiso [Sustantivo predicativo] 》

El verbo compuesto suele estar asociado morfológicamente con un 
verbo simple." En el caso de «dar permiso», el verbo simple morfológicamente asociado es el verbo «permitir». A los verbos compuestos «dar un paseo», «dar un beso» y «tomar una decisión» corresponden los verbos simples «pasear», «besar» $\mathrm{y}$ «decidir» respectivamente. Pero no todos los verbos compuestos presentan este rasgo, como puede observarse en el caso del verbo compuesto «tomar la iniciativa», que no tiene un verbo correspondiente (*iniciativar).

\section{1-3. Sustantivo concreto y sustantivo predicativo}

En una oración normal con un sustantivo concreto-(5)-, es el verbo el que exige el tipo de sujeto y complementos, mientras que en el (6) el sustantivo predicativo «consejo» selecciona su verbo soporte «dar», y el conjunto verbal «dar consejo» exige su sujeto y su complemento.

(5) Pedro dio un reloj a Marta. [sustantivo concreto]

(6) Pedro dio un consejo a Marta. [sustantivo predicativo]

Veamos otro ejemplo. Se dice «dar un paseo»-(7)-, pero no se dice «dar una excursión»-(8)-, sino «hacer una excursión»-(9)-. ${ }^{5)}$ Esto demuestra que en las expresiones «dar un paseo» y «hacer una excursión» no son los verbos los que eligen el tipo de sustantivos, sino al revés. Es decir, el sustantivo «paseo» exige «dar» como verbo soporte, pero el sustantivo «excursión» no selecciona «dar», sino «hacer»:

(7) Juan dio un paseo.

(8) *Juan dio una excursión.

(9) Juan hizo una excursión.

Otro rasgo importante del verbo compuesto es que el sustantivo predicativo conserva plenamente su significado y puede aparecer en otro contexto que no sea en el verbo compuesto. Malero y Gracia (1990) dice que el sustantivo "conserva plenamente su significado y puede ser utilizado en otros contextos con el mismo valor" y cita los ejemplos (10) y $(11)^{6)}$ :

(10) Los paseos por la montaña son muy agradables.

(11) Las excursiones por la montaña son muy agradables. 


\section{1-4. Sujeto}

En el verbo compuesto coinciden el sujeto morfológico del verbo soporte y el sujeto semántico del sustantivo predicativo.?

(12) Pedro dio un consejo a Marta.

(13) *Pedro dio el paseo de Juan por el bosque. (Malero y Gracia, 1990, p.658)

En el ejemplo (12), "Pedro" es el sujeto semántico de «consejo» y el sujeto morfológico de «dio». Si se añade al sustantivo un elemento que no se refiera al sujeto, la oración queda agramaticalizada. Véase el ejemplo (13).

La construcción de verbo soporte no debe ser compleja, ni debe ser segmentada en dos o más frases simples. ${ }^{8)}$ El ejemplo (14), que expresa un contenido equivalente al (16), puede dividirse en dos segmentos- (15)-, por lo que «reconocer un error» no es un verbo compuesto.

(14) Pedro reconoció su error.

(15) Pedro cometió un error. + Pedro reconoció eso. ("cometió" es un Vsop.)

(16) Pedro reconoció el error que había cometido.

Gross, G. (1989, p. 61) dice que "L'emploi d'un verbe ordinaire implique de toute façon, avec un substantif prédicatif, un verbe support, présent ou éffacé." (El empleo de un verbo ordinario implica, de todas maneras, cuando aparece con un sustantivo predicativo, la presencia de un verbo soporte, sea explícito o sea implícito.) El ejemplo (14), donde aparece un verbo ordinario "reconocer", implica un verbo soporte implícito "cometer", en cambio en el (16) aparece un verbo soporte explícito.

\section{1-5. Determinantes}

No es posible aplicar en el verbo compuesto algún determinante que no se refiera al sujeto:"9)

(17) *Laura le dio tu [mi] beso a Pedro. (Oración con Vsop.)

(18) Laura le dio tu [mi] regalo a Pedro. (Oración con verbo léxico) 


\section{1-6. Mantenimiento de los argumentos}

Entre la construcción de verbo soporte y la de un verbo simple correspondiente, la forma de argumentos suele permanecer constante, aunque puede haber una aparición de alguna preposición. ${ }^{10)}$

(19) Pedro aconsejó a Marta.

(20) Pedro dio un consejo a Marta.

Tanto el verbo simple «aconsejar» como el compuesto «dar un consejo» pueden tener el mismo número de argumentos: el que da un consejo y el que lo recibe. Compárense los ejemplos (19) y (20).

\section{1-7. Tematización}

La construcción de verbo soporte admite dos posibilidades de tematización: se puede extraer el conjunto del sustantivo predicativo y su complemento, y también se puede tematizar sólo el sustantivo predicativo. La construcción de verbos normales suele tolerar sólo la primera extracción. ${ }^{11)}$

(21) Pedro dio un apoyo importante a este proyecto.

(22) Fue un apoyo importante a este proyecto lo que dio Pedro.

(23) Fue un apoyo importante lo que dio Pedro a este proyecto.

(24) Pedro alabó tu apoyo a este proyecto.

(25) Fue tu apoyo a este proyecto lo que alabó Pedro.

(26) *Fue tu apoyo lo que alabó Pedro a este proyecto.

(27) Pedro oyó fuertes golpes en la puerta.

(28) Fueron fuertes golpes en la puerta lo que oyó Pedro.

(29) ??Fueron fuertes golpes lo que oyó Pedro en la puerta.

Del ejemplo (21), que es una construcción de verbo soporte, se puede extraer tanto "un apoyo importante a este proyecto" - (22)-como "un apoyo importante" -(23)-, mientras que las oraciones (24) y (27) admiten sólo la extracción de "tu apoyo a este proyecto"-(25)- y "fuertes golpes en la puerta"-(28)-respectivamente. ${ }^{12)}$

Hemos visto hasta aquí algunos rasgos que caracterizan al verbo compuesto formado por un verbo y un sustantivo. En resumen, podemos 
decir lo siguiente: $\mathrm{El}$ verbo soporte es exigido por el sustantivo, al que a su vez hace funcionar como un verbo. Y cualquier sustantivo predicativo tiene su verbo soporte, por lo menos, teóricamente. En el verbo compuesto son los sustantivos predicativos, que suelen estar asociados morfológicamente con verbos simples, los que aportan el principal contenido semántico (lexema principal) y los que seleccionan el tipo de verbo, mientras que el verbo, que contiene información morfológica (persona, número, tiempo, modo, etc.), es un soporte sintáctico que permite que la unidad pueda funcionar como un verbo.

\section{Verbos soporte}

\section{2-1. Verbos soporte fundamentales}

Suponemos que el sistema de los verbos soporte del español está formado por los verbos soporte fundamentales y sus variantes, tesis defendida por Gross, G. (1989, p.170). Ogata (1991) cita "avoir", "être prép." y "faire" como verbos soporte fundamentales del francés, y Malero y Gracia (1990), que no hace esta distinción, considera como verbos soporte "dar", "tomar", "hacer", "poner", "echar" y pocos más.

\section{2-2. Elección del verbo soporte}

Ya hemos visto que es el sustantivo el que exige su verbo soporte en el verbo compuesto. En este apartado queremos aclarar en qué criterios se basa la elección de verbo soporte.

\section{2-2-1. Moliner (1982)}

Moliner (1982), en la entrada de «hacer» de su diccionario de uso del español, dice que «aún tratándose de casos no distinguibles en una definición, en unos casos se emplea «hacer» y en otros «dar» u otro verbo: se dice 'hacer un movimiento', pero 'dar un salto'; 'hacer un propósito', pero 'tomar una determinación'.» Casos como éste pueden encontrarse no con mucha dificultad: dar un aviso-hacer una advertencia, dar un paseo -hacer un viaje, dar un beso-hacer caricias, dar un pellizco-hacer cosquillas, dar un escándalo-armar un jaleo, etc. Después de haber 
hablado de la ausencia de razones claras para la elección entre «dar» y «hacer», Moliner (1982), en la cuarta acepción de la misma entrada de «hacer», menciona la distinción de uso entre «dar» $\mathrm{y}$ «hacer», y dice lo siguiente:

«Se emplea generalmente «hacer» cuando la cosa hecha está expresada por un nombre verbal de acción; entonces, «hacer» más el nombre equivalen al verbo correspondiente: 'Hacer la comunión (comulgar), Hacer gestiones (gestionar)'. Menos general es el empleo de «hacer» cuando el nombre, aunque sea de acción, no es verbal; se dice 'hacer un donativo, hacer un viaje'. Pero en cambio, 'dar un paseo, dar una vuelta, tomar una resolución'. Cuando hay un complemento de persona, unas veces se emplea «hacer»y otras «dar»; se dice 'hacer mimos [caricias] a alguien; pero 'dar besos [abrazos, friegas]'.»

Resulta poco clara la elección de un verbo u otro.

\section{2-2-2. Dubsky (1990)}

Dubský (1990, p.111) , que no emplea el término "verbos compuestos", sino "verbos formemáticos", nos presenta una serie de combinaciones de unos sustantivos con determinados verbos, especificando los rasgos semánticos de los sustantivos. Abajo se indican algunas combinaciones:

dar + sustantivos de acción, movimiento, sonido

hacer (efectuar, fabricar, realizar)+ sustantivos de acción abstracta o movimiento, etc.

tener (sentir, recibir) + sustantivos de acción o movimiento, estado, etc. tomar, coger, cobrar + sustantivos de comienzo de acción o de acción concreta

echar, dirigir, enviar, lanzar + sustantivos de acción abstracta o de acción concreta, sustantivos de movimiento o sonido, etc.

estar, ser + sustantivos de acción abstracta o adjetivos de estado, etc.

De esta lista se deduce que los sustantivos exigen su verbo soporte según su rasgo semántico, hecho lingüístico que es fácil de comprobar cuando 
observamos, por ejemplo, que los sustantivos que expresan «voz»o «sonido» como "aullido", "bufido", "chillido", "gruñido", "ladrido", "mugido", "relincho", etc. y los que expresan «golpe» como "golpe", "bofetada”, “codazo", "manotazo", "portazo", "puñetazo", etc. exigen «dar», no «hacer», para poder funcionar como un verbo. Pero Dubský (1990) se limita a presentarnos dicha lista y no profundiza en el tema, porque, según su lista, los sustantivos de movimiento pueden ser compatibles tanto con «dar» como con «hacer». La distinción sigue sin solución.

\section{2-2-3. Función semántica}

Es cierto que determinados sustantivos exigen su verbo soporte, pero hablando con más precisión, debemos decir que determinados rasgos semánticos del sustantivo seleccionan el verbo soporte. Por ejemplo, el sustantivo «conferencia» exige «dar» cuando significa «una disertación en público sobre un tema cultural», pero cuando significa «una comunicación telefónica entre poblaciones distintas», exige «poner»o «hacer». Así pasa lo mismo con las parejas «dar excusas (pretexto que se da para hacer o dejar de hacer algo)-presentar excusas (justificación que se alega por haber hecho o dejado de hacer algo o explicación que se da a alguien para desagraviarlo)», «dar reparo (dificultad, inconveniente que se encuentra para hacer algo, y que proviene de miedo, timidez o aprensión) - poner reparos (observación que se hace a algo, especialmente si señala una falta o defecto)», etc.

No obstante, hay sustantivos como "oferta" que exigen un verbo soporte para representar significados diferentes. La expresión «hacer una oferta» puede significar tanto "hacer proposición que se hace a alguien o promesa de dar o de hacer algo" (=ofrecer) como "hacer ofrecimiento de algo en venta" (=ofertar).

Parece que hay muy pocos sustantivos predicativos que admiten tanto «dar» como «hacer», sin que cambie su acepción. El sustantivo "viraje" es uno de los pocos sustantivos que se combinan con estos dos verbos $^{13)}$ : 
(30) El autobús dio un viraje brusco y se metió en la plaza.

(Torrente Ballester, III -273)

(31) El conductor, para no atropellar al perro, tuvo que hacer un brusco viraje.(Ken)

Pero hay que tener en cuenta que el uso de un verbo $u$ otro con un mismo sustantivo no refleja siempre la oposición de un verbo soporte y otro soporte, sino, a veces, la oposición entre un verbo soporte y otro léxico. El verbo «dar» funciona como un verbo léxico en la expresión «dar un regalo», pero funciona como soporte en «hacer un regalo» (= regalar).

De dicha observación podemos afirmar, por lo menos, una cosa: que cada acepción de un sustantivo elige su verbo soporte. Esto demuestra que el tipo de verbo soporte sirve para distinguir el significado del sustantivo, cuando éste tiene más de una acepción. Y para hablar de la elección de verbo soporte de un sustantivo predicativo que tenga más de una acepción, es necesario tener en cuenta de cuál de las acepciones se está tratando.

\section{2-3. Variantes}

Gross, G. (1989, p.170) habla de las variantes del verbo soporte francés «donner» («dar» en español), y las divide en cuatro grupos: las variantes estilísticas, las aspectuales, las iterativas y las recíprocas. Suponemos que el concepto de las variantes puede aplicarse también al español.

El hecho de que algunos sustantivos puedan seleccionar tanto «dar» como otro verbo puede explicarse si se introduce el concepto de las variantes. Por ejemplo, el verbo «administrar» de «administrar un golpe» es una variante estilística del soporte «dar». Pueden observarse algunas variantes estilísticas del verbo «dar» cuando aparece con los sustantivos que expresan «golpe»: asentar [largar] una bofetada, un bofetón // descargar un puñetazo // pegar un portazo, una torta // pegar, arrear una paliza, un sopapo. ${ }^{14)}$

Las variantes aspectuales denotan diferencias aspectuales como el 
valor incoativo, durativo, etc. Las expresiones "ponerse en actitud de algo" es una variante aspectual de valor incoativo de "tomar una actitud de algo" y "tener un mareo", una variante aspectual de valor durativo de «dar un mareo».

\section{Los verbos compuestos "Verbo +SP/Adj.»}

Vamos a estudiar las características gramaticales de otros sintagmas verbales de los tipos «Verbo+sintagma preposicional» $\mathrm{y}$ «Verbo + adjetivo», que pueden incluirse en la categoría del verbo compuesto.

\section{3-1.Verbo + Sintagma prep. $+(. .$.}

Empecemos por observar algunas características del sintagma verbal «poner en escena» como ejemplo de esta estructura:

a) Tiene un verbo simple cuya raíz léxica se corresponde con la del sustantivo que forma el sintagma preposicional "en escena" (correspondencia morfológica al verbo simple):

(32) Han escenificado una de las mejores obras del siglo XVIII.

(33) Han puesto en escena una de las mejores obras del siglo XVIII. (P)

b) Tanto el verbo simple «escenificar» como el compuesto «poner en escena» tienen el mismo número de argumentos: el que pone en escena y alguna obra que se pone en escena (mantenimiento de los argumentos).

c) No admite sustituir el verbo "poner" por otro verbo, lo cual demuestra que es el sintagma preposicional lo que exige el tipo de verbo, no al revés:

(34) *Han colocado en escena una de las mejores obras del siglo XVIII.

d) Permite dos tipos de sustantivación, en lo que se diferencia de la estructura «Verbo + sustantivo», que sólo admite uno.

(35) La puesta en escena de una de las mejores obras del siglo XVIII. 
(36) La escenificación de una de las mejores obras del siglo XVIII.

e) A diferencia de la estructura «Verbo+sustantivo», parece difícil aplicar alguna modificación al sustantivo:

(37) *Han puesto en una escena magnífica una de las mejores obras del siglo XVIII.

f) En cuanto a la tematización, no tolera más que la extracción del sustantivo en función de complemento directo:

(38) Ha sido una de las mejores obras del siglo XVIII la que han puesto en escena.

g) Puede transformarse en una construcción pasiva:

(39) Ha sido puesta en escena una de las mejores obras del siglo XVIII.

Por último, queremos confirmar la capacidad productiva de esta estructura como la de «Verbo + sustantivo». La estructura «poner...en...» es capaz de producir las expresiones como "poner en órbita (un satélite)", "poner en servicio (una autopista)", que pueden a su vez sustantivarse -(40)-, o pueden transformarse en voz pasiva-(41)-:

(40) Aunque la puesta en servicio de los cinturones de ronda permite pronosticar una mejora de la circulación, [...] (El País Internacional, 05-08-91)

(41) $[\ldots]$, otro (satélite) similar será puesto en órbita en abril de 1993. (El País Internacional, 14-09-92)

\section{3-2. Verbo + Adjetivo $+(\ldots)$}

Pasemos a repasar las características de la expresión «hacer público (algo)» como ejemplo de la estructura «Verbo + adjetivo»:

a) La expresión "hacer público" tiene un verbo simple cuya raíz léxica se corresponde con la del adjetivo "público" (correspondencia morfológica al verbo simple): 
(42) Ayer la empresa publicó los nuevos nombramientos y los ascensos.

(43) Ayer la empresa hizo públicos los nuevos nombramientos y los ascensos. (Montero, 88, ejemplo modificado)

b) Tanto el verbo simple «publicar» como el compuesto «hacer público» tienen el mismo número de argumentos: el que hace público algo y alguna cosa que se hace pública (mantenimiento de los argumentos).

c) En esta construcción no se puede hablar del sujeto semántico del adjetivo "público", que concuerda en género y número con el sustantivo en función de complemento directo.

d) No puede sustituirse el verbo "hacer" por otro verbo, lo cual demuestra que es el sintagma verbal lo que exige el tipo de verbo, no al revés.

(44) * Ayer la empresa dio públicos los nuevos nombramientos [...] .

e) Existe sólo un tipo de sustantivación, igual que en la estructura «Verbo + sustantivo»:

(45) la publicación de los nuevos nombramientos por la empresa

f) Parece imposible aplicar alguna modificación a "público" por ser un adjetivo.

g) En cuanto a la tematización, no tolera más que la extracción del sustantivo:

(46) Fueron los nuevos nombramientos lo que la empresa hizo público ayer.

h) Puede transformarse en una construcción pasiva:

(47) Ayer los nuevos nombramientos fueron hechos públicos por la empresa. 
Al observar dichos comportamientos sintácticos y morfológicos de las estructuras «Verbo+sintagma preposicional» y «Verbo+adjetivo», descubrimos que estas dos estructuras tienen una tendencia semejante, aunque no idéntica, a la de «Verbo + sustantivo predicativo», porque las tres estructuras presentan las características que pueden resumirse de la manera siguiente:

-El peso semántico está en el componente no verbal, que exige léxicamente el verbo.

-Presentan una cierta flexibilidad formal frente a la locución verbal que no suele aceptar una modificación formal como la tematización, la pasivización, la sustantivación, etc.

-Son estructuras capaces de producir nuevos sintagmas verbales, formando así un conjunto abierto. (Una capacidad productiva)

A continuación intentamos resumir las posibles estructuras de los verbos compuestos.

\section{Posibles estructuras sintácticas de los verbos compuestos}

Las posibles estructuras de los verbos compuestos pueden resumirse en los tres principales tipos siguientes:

I. Verbo soporte + Sustantivo predicativo (+ prep....) dar alcance (a uno) [=alcanzar], poner término (a algo) [=terminar] // dar muerte (a uno) [=matar] // dar posesión (de algo) [= posesionar de] // hacer alarde (de algo) [=alardear de], dar un paseo por $[=$ pasear por] , etc., // hacerse cargo (de...) [=encargarse de] // dar saltos $[=$ saltar $]$, tomar la iniciativa $[=\phi]$

II. Verbo soporte + Sintagma preposicional $+(\ldots)$

poner en orden (algo) [=ordenar], poner en libertad (a alguien) [= liberar], poner en duda (algo) [=dudar] // poner en práctica (algo) [= $\phi] / /$ emprenderla a bofetadas (con alguien) [=abofetear] // dar \{la tos $\}$ (a uno) [=toser] // andar con bromas [=bromear(se)] // venir en conocimiento de (algo) [= conocer] // estar de viaje [= viajar] // estar en contradicción con (algo) [= contradecir]

III. Verbo soporte + Adjetivo $+(. .$. 
hacer público (algo) [=publicar] // poner colérico (a alguien) [= encolerizar] // caer enfermo [= enfermar]

Los verbos compuestos del grupo I están formados por un verbo soporte y un sustantivo predicativo, y algunos de ellos pueden ir seguidos de una preposición para introducir sus complementos. Los sustantivos de este grupo tienen un verbo morfológicamente asociado con un verbo transitivo (hacer un repaso a $\ldots=$ repasar, dar alcance $\mathrm{a}_{\ldots} . .=$ alcanzar) o con un verbo intransitivo (hacer alarde de... =alardear de..., hacer blasón de... =blasonar de...), o no tienen un verbo asociado morfológicamente (dar jaqueca a uno) o tienen un verbo no asociado (dar muerte a uno $=$ matar).

El conjunto «Vsop. + un sintagma preposicional» forma los verbos compuestos del grupo II, que pueden subdividirse en dos según tengan o no una correspondencia léxica con un verbo simple: los que están asociados morfológicamente con un transitivo (poner en orden ...= ordenar, poner en libertad a...=liberar) y los que no tienen ningún verbo morfológicamente asociado (poner en práctica...).

Los del grupo III consisten en un verbo soporte y un adjetivo asociado morfológicamente a un verbo transitivo (hacer difícil ... = dificultar). 


\section{Notas}

*Este texto es una versión revisada de la ponencia que, con el título de "Estructuras de los verbos compuestos", se presentó al XXXVIII Congreso de la Asociación Japonesa de Hispanistas, que se celebró en la Universidad de Estudios Internacionales de Kanda en noviembre de 1992. Quisiera expresar mi agradecimiento a los Sres. Alex Fernández de Castro y Pedro Makabe, quienes han revisado el texto desde el punto de vista de los nativos.

1) Cf. Solé, Y. (1966), Hacer: verbo funcional y lexical, Mémoire de Georgetown University, Institute of Language and Linguistics.

2) Cf. Häusermann, J. (1977), Phraseologie, Linguistische Arbeiten, 47, Tubinga.

3) Cf. Gross, M. (1975), Méthode en syntaxe, Paris: Hermann.

Cf. Gross, G. (1989)

4) Cf. Malero y Gracia (1990) p.656

5) Id.

6) Id.

7) Cf. Gross, G. (1989), p. 38-39.

8) Cf. Gross, G. (1989), p. 39-40.

9) Cf. Gross, G. (1989), p. 41.

10) Cf. Gross, G. (1989), p. 44.

11) Cf. Gross, G. (1989), p. 45-46.

12) De los siete nativos ( 2 españoles, 2 mejicanos, 2 costarricenses y 1 peruano), a los que hemos hecho unas comprobaciones, 6 (excepto un español) dijeron que no dirían el (26) y 2 (un mejicano y un peruano) dijeron que no dirían el (29).

13) Otras expresiones en las que aparecen tanto «dar» como «hacer» son «dar [hacer] un corcovo», «dar [hacer] un giro», «dar [hacer] arrullos», «dar [hacer] escarmiento».

14) En la lista de Dubský (1990, p.111) se pueden encontrar muchas variantes del soporte «dar», aunque él no emplea el término "variante".

\section{Fuentes de los ejemplos citados:}

Ken: Ueda et al. (1992) Nuevo dic. japonés-español, Tokio: Kenkyusha.

Montero, R. (1988), Amado amo, Madrid: Debate

P: Marsá, Francisco (1982), Dic. Planeta de la lengua española usual, Barcelona: Planeta.

Torrente Ballester, G. (1982), Los gozos y las sombras, Madrid: Alianza Ed. 


\section{Bibliografía}

Cano Aguilar, R. (1981), Estructuras sintácticas transitivas en el español actual, Madrid: Gredos.

Casares, J. (1950), Introducción a la lexicografía moderna, Madrid: RFE.

Dubský, Josef (1990), "El campo léxico de los verbos de introducción, de relación, de apoyo y verbos formemáticos", La descripción del verbo español, Verba, anexo 32, Santiago de Compostela: Univ. de Santiago de Compostela.

Giry-Schneider, J. (1987), Les prédicats nominaux en français: les phrases simple's à verbe' support, Genève: Droz.

Gross, G. (1989), Les constructions converses du français, Genève: Droz.

Haensch, G., Wolf, L., Ettinger, S. y Werner, R. (1982), La lexicografía Madrid: Gredos.

Koike, K. (1991a), "Estructuras sintácticas de las locuciones verbales en español (1)", Language Studies, $N^{\circ}$ 64. p.81-99. Tokio: Takushoku Univ.

(1991b), "Estructuras sintácticas de las locuciones verbales en español (2)", Language Studies, $N^{\circ}$ 65. p. 43-71. Tokio:Takushoku Univ.

(1991c), "Las locuciones verbales con CD variable", Estudios Lingiüsticos Hispánicos, Núm. 6. p.105-114. Tokio: CELHT.

(1991d), "Las locuciones verbales en español: $\mathrm{S}+\mathrm{V}+\mathrm{CD}+\mathrm{CI} \quad(=\mathrm{a}+$ Sustantivo)", Hispánica, Núm. 35. p. 46-64. Tokio: Asociación Japonesa de Hispanistas.

Malero, M. y Gracia, O. (1990), "Construcciones de verbo soporte”, Actas del Congreso de la Sociedad Española de Lingüistica, XX Aniversario, Madrid: Gredos.

Ogata, K. (1985), "Ruigi hyogen to sono koubuntokusei" (en japonés), Problemas de la lingüística francesa, Tokio: Sanshu-sha.

(1991) "Maurice Gross", (en japonés), Gekkan Gengo, 1991, 12. p. 88-95. Tokyo: Taishuu-kan.

Wotjak, G. (1988), "Uso y abuso de unidades fraseológicas", Homenaje a Alfonso Zamora Vicente, I., p. 535-548., Madrid: Castalia.

Zuluaga, Alberto (1975a), "Estudios generativo-transformativistas de las expresiones idiomáticas", $B I C C, X X X, N^{\circ} .1$, p.1-48.

(1975b), "La fijación fraseológica", $B I C C, X X X, N^{\circ} .2$, p.225-248. 